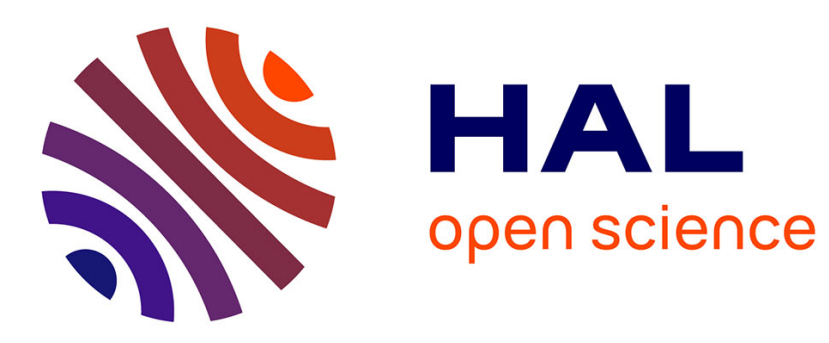

\title{
Ceramic/metal joining for structures and materials
}

A. Tomsia

\section{To cite this version:}

A. Tomsia. Ceramic/metal joining for structures and materials. Journal de Physique IV Proceedings, 1993, 03 (C7), pp.C7-1317-C7-1326. 10.1051/jp4:19937203 . jpa-00251837

\section{HAL Id: jpa-00251837 https://hal.science/jpa-00251837}

Submitted on 1 Jan 1993

HAL is a multi-disciplinary open access archive for the deposit and dissemination of scientific research documents, whether they are published or not. The documents may come from teaching and research institutions in France or abroad, or from public or private research centers.
L'archive ouverte pluridisciplinaire HAL, est destinée au dépôt et à la diffusion de documents scientifiques de niveau recherche, publiés ou non, émanant des établissements d'enseignement et de recherche français ou étrangers, des laboratoires publics ou privés. 


\title{
Ceramic/metal joining for structures and materials
}

\author{
A.P. TOMSIA \\ Lawrence Berkeley Laboratory, Materials Sciences Division, MS 62-203 Berkeley, California 94720, U.S.A.
}

\begin{abstract}
The paper presents a discussion of the various types of ceramic joining within a conceptual framework based on the fundamentals of wetting, adhesion, and the thermodynamics of interfacial reactions. Examples are given of solid state diffusion bonding of $\mathrm{Pt}$ to alumina and brazing of AlN. Most ceramic-metal bonding is conducted at high temperatures, where chemical reaction is to be expected. The way in which bond strength is affected by chemical reaction at ceramic-metal interfaces is also discussed.
\end{abstract}

\section{INTRODUCTION}

Successful application of ceramics in many devices and structures requires some type of ceramicmetal joining. Ceramic-metal seals are used extensively in a wide variety of applications. Examples include vacuum tubes, high voltage feedthroughs, transistor packages, sapphire-metal windows, rocket ignitor bodies and many others. Newer joining applications include engine components, such as the $\mathrm{Si}_{3} \mathrm{~N}_{4}$ turbocharger rotor joined to a metal shaft now being produced commercially, multilayer electronic devices that comprise both ceramics and electrodes, electroding and metallizing of hybrid microcircuit substrates, and ceramic-metal composites. All applications require a high-strength metal-ceramic bond.

Two factors drive the need for the development of improved joining technologies. First, it is difficult to fabricate large ceramic structures with complex shapes. Although small individual pieces of complex shape, such as a turbine rotor, can be fabricated, the path of least technological resistance to developing larger structures will often entail joining assemblies of more easily fabricated small components. Second, although ceramics may possess a unique and desirable set of properties, there will be applications in which these properties are needed and desirable not for an entire structure, but only in one portion of a structure. For these applications, it will be necessary to join the ceramic to either another ceramic, or to a metal. The development of viable joining techniques will facilitate the assimilation of advanced ceramics into complex multimaterial structures.

\section{INTERFACE FORMATION AND STRENGTH IN CERAMIC-METAL SYSTEMS}

The key step in the formation of a ceramic/metal interface is to achieve adequate contact between the two materials at the interface. The driving force for the formation of a ceramic/metal interface is the reduction in free energy when intimate contact is established between the ceramic and metal surfaces. In order for this to happen, both surfaces have to be brought into intimate contact which is usually accomplished by controlling the temperature and atmosphere during interface formation. A solid/solid 
interface in which at least one of the surfaces is a metal can be formed by pressure, especially at an elevated temperature, resulting in displacement of impurities and adjustment of irregularities due to localized deformation. A solid/liquid interface can be formed and recognized easily if the liquid wets or spreads thereby penetrating between irregularities at the solid surface.

It has been widely considered that wetting is an essential prerequisite for the making of a good bond. It is understood, however, that wetting alone is not sufficient to guarantee good adhesion since wetting can occur with either van der Waals or stronger "chemical" bonding across the interface. Chemical bonding is usually associated with a low contact angle in a sessile drop experiment wherein the liquid itself has strong bonds. Moreover, it has been found more recently that, although difficult to make, bonds between ceramics and highly ductile, noble metals can be strong despite the poor wetting characteristics exhibited.

Contact angle phenomena are complex and their interpretation is to some extent still controversial. The terms "wetting", "non-wetting" and "spreading" tend to be defined differently by various researchers. In most cases, however, wetting means that the contact angle between a liquid and a solid is between $0^{\circ}$ and $90^{\circ}$, non-wetting means that the angle is greater than $90^{\circ}$ and spreading means that the contact angle is nominally zero and the liquid spreads over the solid easily. Sessile drop experiments with proper interpretation are important because they provide valuable information on the formation of intimate interfaces and the existence of reactions which normally may be unrecognized and overlooked. It is thus worthwhile to examine and understand the associated principles.

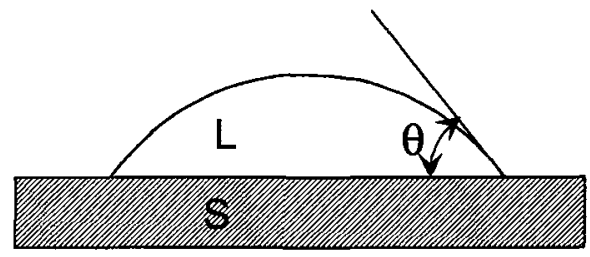

$0<\theta<90^{\circ}$

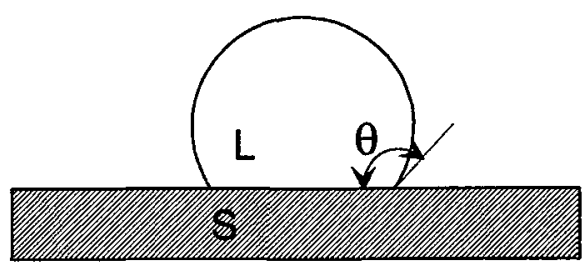

$180^{\circ}>\theta>90^{\circ}$

Figure 1. Sessile drop configurations. $\mathrm{L}$ - liquid, $\mathrm{S}$ - solid, $\theta$ - contact angle.

The sessile drop technique is used extensively in the study of glass/metal sealing and ceramic/metal brazing. Figure 1 is a schematic of cross-sections of a wetting and non-wetting sessile drop. At equilibrium in the absence of chemical reaction, a liquid will assume a characteristic contact angle, $\theta$ on a solid that is determined by the balance of forces among the liquid surface tension, $\gamma_{l v}$, the solid surface energy, $\gamma_{\mathrm{Sv}}$, and the energy of the solid-liquid interface, $\gamma_{\mathrm{sl}}$. The balance of forces is given by the Young-Dupré equation [1]. Wetting occurs when the surface energy of the solid exposed to the atmosphere is greater than that of the interface.

$$
\gamma_{\mathrm{sv}}-\gamma_{\mathrm{sl}}=\gamma_{\mathrm{lv}} \cos \theta
$$

Absence of a steady-state contact angle is usually taken as evidence that reactions are occurring between the drop and the substrate and that they are not at equilibrium. Often the contact angle diminishes with time, over times much longer than needed simply for viscous flow of the liquid. Although not well understood, the reactions that can lead to low contact angle range from extension of the liquid simply to adjust the segregant on the solid surface to formation of new phases or compounds. If a reaction takes place at the interface the $\Delta \mathrm{G}_{\mathrm{R}}$ (free energy of reaction) contributes to the driving force for wetting. The equality in the equation is lost and a dynamic situation arises wherein the driving force for wetting approaches $\gamma_{v}$, with a decrease in contact angle $\theta$. When the force exceeds $\gamma_{l v}, \theta$ becomes zero and the liquid continues to spread. 
Significant experience has shown that there is often a correlation between low contact angles and good joint strength. Although not fully understood, several factors may be important. Obviously, good wetting expedites obtaining a high fraction of bonded area and low stress concentrations. In a braze, this is reflected as good fill and also fillets with low stress concentrations. In pressure bonding of solids, low $\theta$ should not only correlate with higher driving force for pore removal, but also a much more benign shape for residual interface pores, in contrast to the near crack like shapes associated with high contact angles. This may be critical as the inevitable residual pores may be the strength limiting flaws.

However, a fundamental correlation between good interface bonding and high strength is widely anticipated. If no chemical reaction takes place at the ceramic/metal interface, and there is negligible plastic flow in the metal or other dissipation during failure of a ceramic/metal joint, the energy to separate a ceramic/metal interface has been equated to the work of adhesion, $W_{\text {ad }}$. Work of adhesion strictly represents the free energy change to reversibly form an interface from two surfaces, metal and ceramic. The work of adhesion of a liquid on a solid may be calculated as the sum of work performed in generating one unit area of liquid surface and one unit area of solid surface minus the original solid-liquid interfacial energy. The result is expressed by Dupré's equation:

$$
\mathrm{w}_{\mathrm{ad}}=\gamma_{\mathrm{sv}}+\gamma_{\mathrm{lv}}-\gamma_{\mathrm{sl}}
$$

Substituting the Young's equation into the expression for the work of adhesion gives:

$$
\mathrm{W}_{\mathrm{ad}}=\eta_{\mathrm{v}}(1+\cos \theta)
$$

For a given ceramic, one predicts that metals with high surface energies that form low energy ceramic/metal interfaces would form the strongest bonds. Higher melting point metals tend to have higher surface energies, and thus, might be expected to form stronger bonds. Direct measurement of $\mathrm{W}_{\mathrm{ad}}$ is not possible [2]. Indirectly, the work of adhesion can be determined from a measurement of the contact angle if the surface energy (or surface tension) of the liquid in equilibrium with its vapor is known. (This presumes the melting point of the metal is sufficiently less than that of the ceramic that an equilibrium shaped metal can be obtained before the ceramic can deform or dissolve discernably. Any correlation with low temperature strength also neglects the role of the temperature and atmosphere dependence on $\theta$ and $\gamma$ lv, which are often strong.) Equation (3) indicates that the work of adhesion is dependent on the contact angle. The ceramic/metal interfacial energy decreases as the work of adhesion, $W_{\text {ad }}$ increases. Thus, improvement in the ceramic/metal bond strength results in an interfacial energy decrease. The work of adhesion has been calculated from first principles for different metals on $\mathrm{Al}_{2} \mathrm{O}_{3}[3,4]$. Good agreement was found between the calculated and experimentally measured values (based on Eq. (3)) for that particular study. However, adhesion is a complex phenomenon that is difficult to model theoretically for systems of practical interest.

\section{SOLID-STATE CERAMIC/METAL PRESSURE BONDING}

Solid-state pressure bonding has been applied to the joining of ceramics to ceramics and ceramics to metals [5-11]. Two macroscopically flat surfaces are brought into contact at an elevated temperature, generally $\geq 0.5$ of the absolute melting temperature $\left(T_{m}\right)$ of the less refractory component, until a strong joint is formed. Successful pressure bonding relies upon the achievement of adequate interfacial contact, and subsequent diffusion or plastic flow to eliminate interfacial porosity. When both materials undergo limited plastic flow (e.g., ceramic-ceramic bonding) or when deformation of the workpiece must be avoided (e.g., the niobium-sapphire bond in high pressure sodium lamps) special care must be taken to assure smooth mating surfaces [12]. When ceramic-metal bonds are being formed, and deformation of the metal is permissible, plastic flow generally occurs within the metal. 
Increasing either the fabrication pressure or time generally improves the quality of the joint, as measured by the failure strength of the assembly. However, of the processing parameters that can be controlled, temperature appears to be the most important. Nicholas reports that an increase in the joining temperature of $T_{m} / 10$ (where $T_{m}$ is the melting temperature in Kelvins) can make the difference between a low strength and high strength assembly [13]. Although increases in time and temperature can improve the joint quality, there are limits. Initially, chemical reactions at the interface often have a favorable effect. However, if the time and temperature are excessive, thick interfacial reaction product layers can form. These layers can generate volume mismatch strains and stresses at the interface that are of sufficient magnitude to degrade assembly strength [14].

The advantages of solid state pressure bonding include a simple fabrication procedure, a one-step process, and potentially very high joint strength. However, there are also several limitations and disadvantages: high cost, only flat specimens can be joined, a vacuum/inert atmosphere is required, and pressure must be applied. The need to apply pressure during diffusion bonding imposes restrictions on the joint geometry; most joints are of the face seal type, and are not well suited for accommodating thermal expansion mismatch. As a result, the bonded components must either be small, one component must be thin [7,9,11], or the thermal expansion coefficients of the components must be well matched. The use of graded thermal expansion laminates for bonding materials with highly dissimilar thermal expansion coefficients is one method of overcoming this limitation [5].

\section{Solid-State Joining of Platinum to Alumina}

Bonding Pt to alumina provides a representative example of solid-state pressure bonding. Platinum/alumina bonding was carried out by placing a thin $\mathrm{Pt}$ foil between two $\mathrm{Al}_{2} \mathrm{O}_{3}$ surfaces (sometimes precoated with $1000 \mathrm{~nm}$ of $\mathrm{Pt}$ ), and exposing the sandwich to normal compressive stress $(\approx$ $1 \mathrm{MPa}$ ) in an argon atmosphere at $1450^{\circ} \mathrm{C}$. Three grades of polycrystalline alumina were used in the study: $\mathrm{L}-\mathrm{Al}_{2} \mathrm{O}_{3}(96 \%) ; \mathrm{H}_{-} \mathrm{Al}_{2} \mathrm{O}_{3}(99 \%)$; and $\mathrm{HP} \mathrm{Al} \mathrm{O}_{3}$ (99.9\% hot-pressed). The metal foil thicknesses ranged between 25 and $250 \mu \mathrm{m}$. Fracture tests were conducted in four point flexure, using a minimum of 12 beams from each bond, and the resulting fracture surfaces were examined in the SEM and TEM.
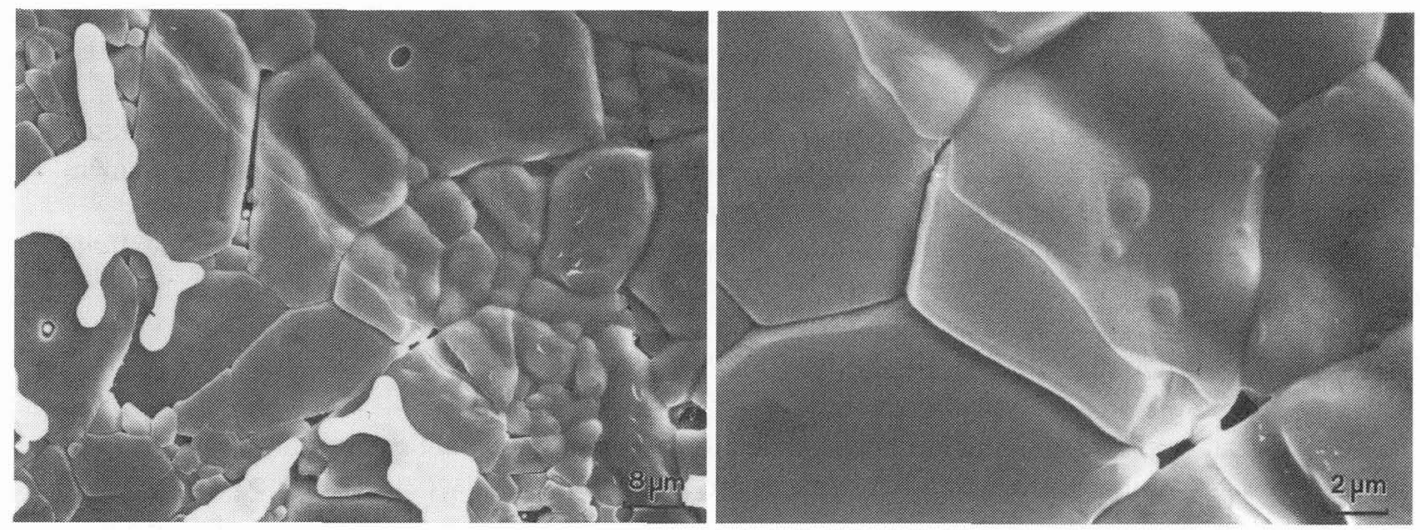

Figure 2. SEM of the ceramic fracture surface from a bond between $\mathrm{Pt}$ and commercial grade $\mathrm{Al}_{2} \mathrm{O}_{3}$. (left) an area of $\mathrm{Al}_{2} \mathrm{O}_{3}$ that was not in contact with Pt during bonding; (right) The surface glaze on $\mathrm{Al}_{2} \mathrm{O}_{3}$ shown at higher magnification [15].

SEM observations of interface fracture surfaces of $\mathrm{L}-\mathrm{Al}_{2} \mathrm{O}_{3} / \mathrm{Pt}$ indicated the presence of microstructural defects on the ceramic side in the form of inherent pores. Additionally, while a thin layer of glass covers most of the ceramic surface, regions devoid of glass are presumed to be incompletely 
bonded, and therefore, microstructural defects. It is presumed that these defects are the fracture origins. The glass appears to diffuse from the bulk alumina, "wets" the interface and, at the same time, replicates the alumina grain structure on the metal side. X-ray Photoelectron Spectroscopy (XPS) of $\mathrm{L}-\mathrm{Al}_{2} \mathrm{O}_{3} / \mathrm{Pt}$ fracture surfaces revealed the presence of $\mathrm{Pt}, \mathrm{Si}, \mathrm{SiO}_{2}, \mathrm{Na}$ and $\mathrm{Ca}$ on the $\mathrm{Pt}$ side, and on the $\mathrm{Al}_{2} \mathrm{O}_{3}$ side, $\mathrm{O}, \mathrm{Al}, \mathrm{Si}, \mathrm{Pb}, \mathrm{Ca}$, and $\mathrm{Na}$, with the $\mathrm{Si} / \mathrm{Al}$ ratio decreasing rapidly with profiling depth.

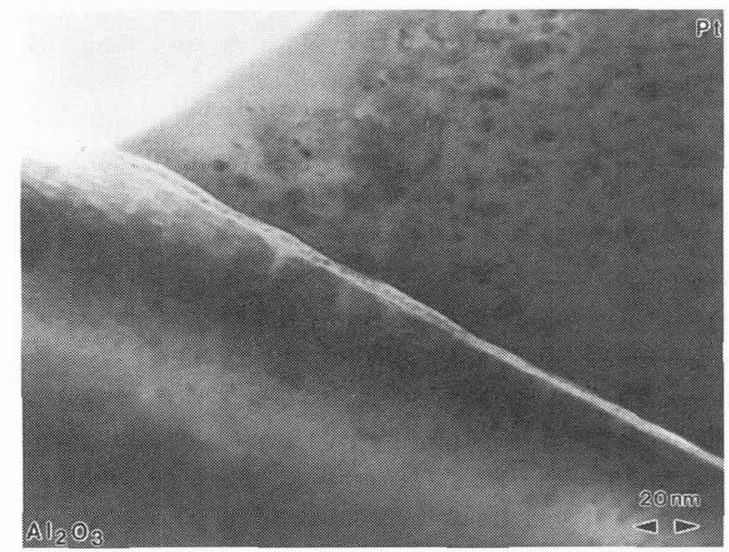

Figure 3. TEM cross-section of $\mathrm{Pt}-\mathrm{Al}_{2} \mathrm{O}_{3}$ bond with amorphous glassy phase at the interface [15].

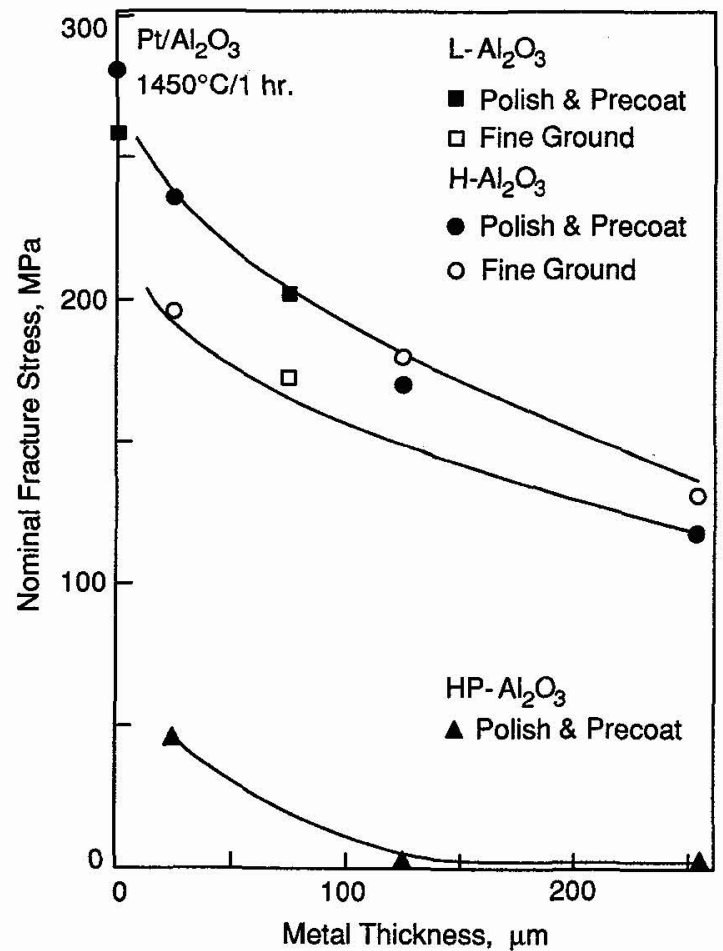

Figure 4. Nominal fracture stress versus $P t$ foil thickness. The effects of alumina purity and sample preparation on bond strength were also explored [15].
SEM observations suggest that the glass is drawn to the $\mathrm{Al}_{2} \mathrm{O}_{3} / \mathrm{Pt}$ interface. The left hand side of Figure 2 shows an area of $\mathrm{Al}_{2} \mathrm{O}_{3}$ that was not in contact with $\mathrm{Pt}$ during diffusion bonding, i.e., a free surface (achieved by indenting the Pt foil prior to bonding). In this region, grain surfaces and boundaries are clean compared with the adjoining region. The surface glaze is shown at higher magnification in Figure 2. Additionally, the white regions on the free surface which form by the disruption of the original $\mathrm{Pt}$ precoat are also underlayed with glass. Transmission electron microscopy (Figure 3) confirmed the presence of a thin amorphous phase at $\mathrm{L}-\mathrm{Al}_{2} \mathrm{O}_{3} / \mathrm{Pt}$ and $\mathrm{H}$ $\mathrm{Al}_{2} \mathrm{O}_{3} / \mathrm{Pt}$ interfaces.

\section{$\mathrm{HP}-\mathrm{Al}_{2} \mathrm{O}_{3} / \mathrm{Pt}$ interface fracture surfaces} revealed a theoretically dense fine-grained $(\approx 3 \mu \mathrm{m}$ grain size) ceramic surface, and distributions of voids on the metal side which derive from incomplete diffusion bonding. Again, these defects are presumed to be the fracture origins. Indeed, when short bonding times, i.e., up to $4 \mathrm{~h}$, were employed with the HP- $\mathrm{Al}_{2} \mathrm{O}_{3}$, low stress fracture occurred (see Figure 4), and subsequent SEM examination revealed large unbonded areas near the beam tensile surface on the metal side.

Strength tests indicated that all bonds exhibit essentially linear behavior prior to fracture The highest strengths typically corresponded with failure originating within the $\mathrm{Al}_{2} \mathrm{O}_{3}$. Otherwise, fracture occurred at the interface. Mean strength values are plotted in Figure 4; the values for HP$\mathrm{Al}_{2} \mathrm{O}_{3}$ are included for completeness and to illustrate that the absence of silicate impurity requires that extended soak times be employed to achieve significant bond strength. The mean strengths of the $\mathrm{L}-\mathrm{Al}_{2} \mathrm{O}_{3}$ and $\mathrm{H}-\mathrm{Al}_{2} \mathrm{O}_{3}$ were also determined for reference. It is apparent that interfacial failure is sensitive to the metal layer thickness, whereas failure in the ceramic is essentially thickness independent. Ceramic failure 
was observed in some specimens with metal thickness up to $125 \mu \mathrm{m}$. The prior finish on the ceramic contact surface also appears to influence failure, especially for bonds with the thinner metal layers.

In summary, it is evident that $\mathrm{Pt} / \mathrm{Al}_{2} \mathrm{O}_{3}$ bonds having thin metal layers have strenghts comparable to the inherent strength of the ceramic. Very similar results were also reported for solid state pressure bonding of $\mathrm{Au}$ to alumina [16]. Residual interface pores are the major strength limiting flaws. Bonding temperature and time, and ceramic surface finish are important in limiting interfacial flaws. Silicate glass impurity, expedites bonding via improved "wetting". Therefore higher strength in significantly shorter time, can be achieved with impure $\mathrm{Al}_{2} \mathrm{O}_{3}$. However, silicate impurity is not essential for good bond strength. At longer bonding times the best results for $\mathrm{HP}-\mathrm{Al}_{2} \mathrm{O}_{3}$ compare with those for impure $\mathrm{Al}_{2} \mathrm{O}_{3}$.

\section{REACTIVE METAL BRAZING}

Brazing involves bonding via a metallic interlayer. Braze alloys are far more ductile than glasses, and thus more forgiving. In cases where ceramics are being introduced into predominantly metal structures, brazes provide a more familiar joining material. The criteria for selection of brazing alloys are that they must wet or coat the ceramic, must form a chemical bond at the interfaces resulting in a strong joint, and should cause minimal degradation of the base material(s). Successful brazing alloys produce bonds that are: 1) strong, 2) reliable, and 3) relatively inexpensive to manufacture. Brazing techniques are versatile, and can produce vacuum tight joints with high strength and substantial temperature capability. Brazes can often be developed to resist a variety of chemical environments. Brazing also lends itself more readily to mass production than solid-state pressure bonding.

Brazing of ceramics is not without difficulty. In contrast to glasses, many metals and alloys bead up on ceramic substrates, that is the molten metal does not wet the ceramic. To promote wetting, the ceramic surface must either be metallized, or a braze containing a chemically reactive or active metal, often titanium, must be used. Titanium reacts with the ceramic and generally facilitates wetting via the formation of a more metallically bonded reaction product at the interface [17-19]. Results of studies by Nicholas and co-workers as well as others have established that there is a minimum active metal chemical potential or activity, often expressed as a minimum reactive metal content, required to produce a sufficiently low contact angle for brazing [19]. In general, the higher the reactive metal content, the more rapid the decrease in contact angle at temperature, and the lower the ultimate contact angle. However, at progressively higher Ti contents, the thickness of the interfacial reaction layer also increases, often with deleterious effects on joint properties. In addition, solute hardening of the alloy can be detrimental if the thermal expansion mismatch between the braze and the assembly constituents is large; ductile interlayers may be preferable in this situation. Thus, the "optimum" active metal content in conventional reactive metal brazing may represent a compromise between wetting, flow and reaction considerations, and mechanical considerations.

As is the case for any joining process, there are also some important constraints and concerns, many of which are a direct consequence of the presence and action of the reactive metal. The flow of some reactive metal alloys is reported to be sluggish, and as a result, preplacing foils is often necessary. The reactivity of the alloys generally demands that they be used in a vacuum or in an inert atmosphere containing sub-ppm oxygen levels. As is often the case in diffusion bonding, an interfacial reaction product forms. If the brazing time or the brazing temperature is excessive, and the reaction product is brittle or has a significant thermal expansion mismatch with the ceramic, weakening of the joint can result.

\section{$\underline{\text { Reactive Metal Brazing of Aluminum Nitride }}$}

Nonoxide ceramics are being developed for a wide variety of applications, ranging from use as structural components in heat engines to high performance substrates for hybrid microcircuits. Many of 
these applications require development of suitable sealing or joining techniques. Most joining methods use brazing alloys or nonmetallic materials such as reactive ceramics or glasses. Much of the work has focused on the use of metallic brazing alloys as the bonding medium, closely analogous to the brazing techniques used in conventional oxide ceramic joining.

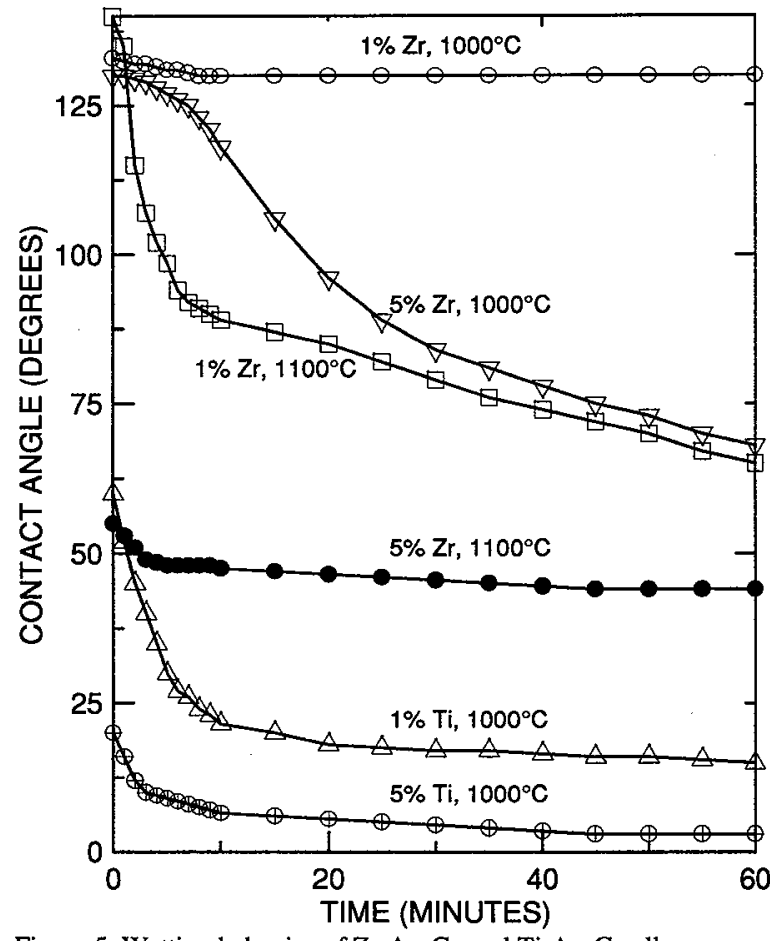

Figure 5. Wetting behavior of $\mathrm{Zr}-\mathrm{Ag}-\mathrm{Cu}$ and $\mathrm{Ti}-\mathrm{Ag}$-Cu alloys on AlN. Compositions indicated on curves are in weight percent.
Since a primary application for aluminum nitride is as a substrate for electronic applications, the focus has been on low temperature brazing, using a variety of commercially available alloys based on the $\mathrm{Cu}-$ Ag-Ti system. Ti is widely used as the reactive element in active metal braze filler alloys that are increasingly being applied for ceramic joining. Other reactive elements, such as $\mathrm{Nb}$, $\mathrm{Al}, \mathrm{Cr}, \mathrm{V}, \mathrm{Ta}$ and $\mathrm{Zr}[20,21]$ also have been investigated in varying levels of detail. The examples used here report a comparative study of the reactions and resulting microstructures for $\mathrm{Ti}$ and $\mathrm{Zr}$ on $\mathrm{AlN}$ [22]. The activities of the $\mathrm{Ti}$ and the $\mathrm{Zr}$ were varied by dissolving them at 1 and $5 \mathrm{wt} . \%$ in the $72 \mathrm{Ag}-28 \mathrm{Cu}$ eutectic.

The results of the contact angle studies of the $\mathrm{Cu}-\mathrm{Ag}$ brazes on AlN are presented in Figure 5. Several features are evident. First, the higher the $\mathrm{Ti}$ or $\mathrm{Zr}$ concentration, the lower the contact angle. Continuous decrease of contact angle with time and spreading are indicative of reaction(s) in sessile drop experiments. Second, for all experimental conditions used, contact angles for the Ti-

containing alloys are lower than for those with $\mathrm{Zr}$. At $1000^{\circ} \mathrm{C}$, the $\mathrm{Zr}$-containing alloys initially melted, but then they rapidly formed a partially solidified drop that was unable to spread significantly on the ceramic. At $1100^{\circ} \mathrm{C}$ the $\mathrm{Zr}$ alloys were liquid and conventional contact angles were observed. This temperature dependence is related to alloy phase behavior as discussed below.

The segregation of an alloy element to the solid-liquid interface is usually an indication of the reduction of $\gamma_{s l}$. While it is possible that segregation alone might sufficiently reduce $\gamma_{s l}$ to produce adequate wetting, there is also clear evidence for the presence of interfacial reaction products that are not accounted for by the Young-Dupré equation. In fact, Yost and Romig [23] have shown that the free energy of formation of an interfacial reaction product $\left(\Delta \mathrm{G}_{\mathrm{R}}\right)$ will be an additional thermodynamic driving force for reducing contact angle. Microstructures and compositions of the reaction zones for reaction of both Ti$\mathrm{Ag}-\mathrm{Cu}$ alloys with AlN were very similar to those previously reported for commercial braze alloys on AlN [24-26]. The microprobe data presented in Figure 6 show a reaction zone adjacent to the alloy about $25 \mu$ $m$ in thickness with the approximate composition $\mathrm{TiN}_{0.7}$. Well away from the ceramic-metal interface, the alloy exhibits the $\mathrm{Ag}-\mathrm{Cu}$ eutectic structure with no Ti; essentially all the Ti has segregated to the interface. Between the $\mathrm{Ag}-\mathrm{Cu}$ eutectic and the $\mathrm{TiN}_{\mathrm{X}}$ layer is the region where previous $\mathrm{TEM}$ studies have

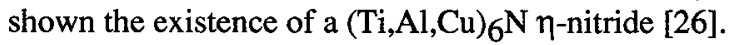



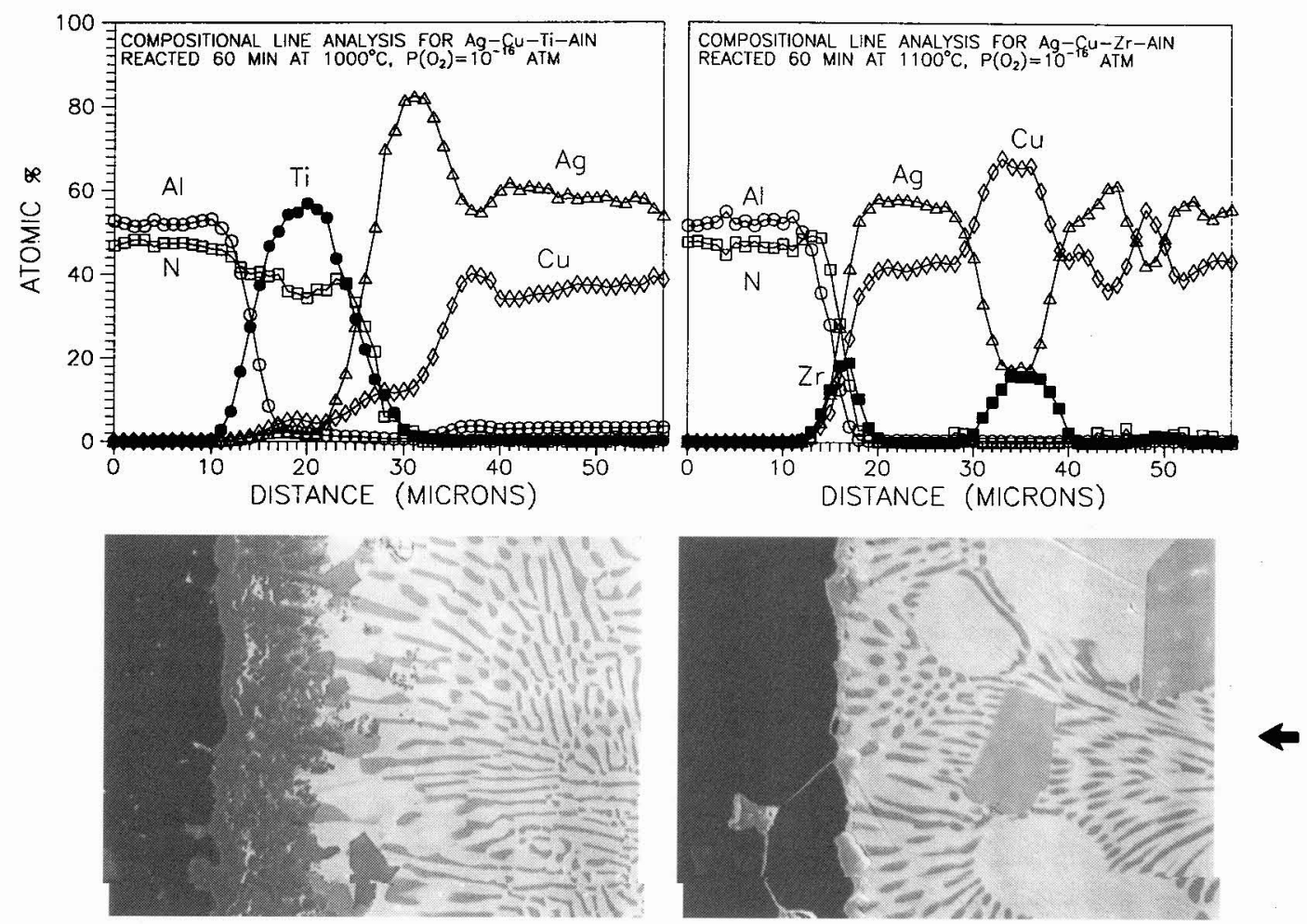

Figure 6. Microprobe compositional line analyses and associated SEM for (left) $\mathrm{Ti}-\mathrm{Ag}-\mathrm{Cu}$ and (right) $\mathrm{Zr}-\mathrm{Ag}-\mathrm{Cu}$ on $\mathrm{AlN}$ reacted for $60 \mathrm{~min}$. at $1000^{\circ} \mathrm{C}$.

The interface resulting from reaction between $4.7 \mathrm{Zr}-57.4 \mathrm{Ag}-37.9 \mathrm{Cu}(\mathrm{wt} . \%)$ and $\mathrm{AlN}$ at $1100^{\circ} \mathrm{C}$ is somewhat different from that of the comparable Ti alloy. One major difference is that the $\mathrm{ZrN}$ reaction zone is only about one-third the thickness of the Ti reaction zone. Another difference is that, within experimental error, the $\mathrm{ZrN}$ layer is stoichiometric. A third difference is that not all the $\mathrm{Zr}$ has segregated to the interface with the ceramic. Grains with the average composition $\mathrm{ZrAgCu}_{3}$ are observed throughout the metal drop.

Additional studies were made of interfacial reactions that could further improve wetting, according to equation (2), by using x-ray photoelectron spectroscopy (XPS) to characterize the interfaces of heattreated Ti-thin films deposited on AIN substrates. XPS is particularly useful for these studies because it is sensitive not only to different elements, but also to their different chemical environments. Figure 7 summarizes some of the thin film results. The Ti2 2 (3a) and $\mathrm{Al} 2 p(3 \mathrm{~b})$ photoelectron spectra shown were obtained from a reaction couple $(80 \mathrm{~nm} \mathrm{Ti}$ on $\mathrm{AlN})$ heated to $900^{\circ} \mathrm{C}$ for $30 \mathrm{~min}$ in argon and from several reference samples. The Ti/AIN couple was sputter-cleaned by an Ar-ion gun to remove an oxidized surface layer and to reveal the reaction products that include TiN (Ti2 $p$ binding energy $\approx 455.0 \mathrm{eV}[27,28]$ ) and a metallic Al-phase (A12p binding energy $\approx 72.3 \mathrm{eV}[28]$ )

The simplest reaction that is consistent with these XPS results is $\mathrm{Ti}+\mathrm{AlN}=\mathrm{TiN}+\mathrm{Al}$. Using tabulated free-energy data, this reaction has a $\Delta G_{R}$ of $-8.8 \mathrm{kcal} / \mathrm{mol}$ at $1200 \mathrm{~K}$ and thus would provide the additional thermodynamic driving force for wetting. 

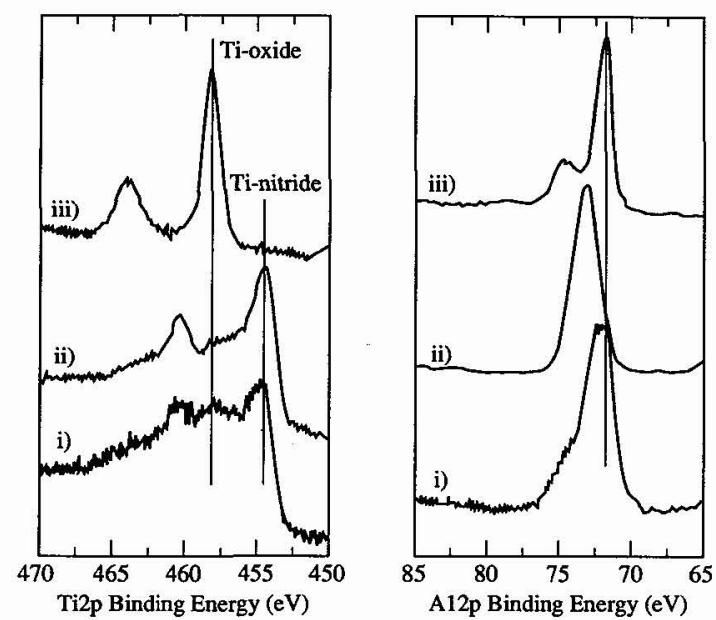

Figure 7. a) Ti2 $2 p$ photoelectron spectra from i) a sputter-cleaned Tithin film/AIN reaction couple and from ii) $\mathrm{TiN}$ and iii) $\mathrm{TiO}_{2}$ reference samples; b) Al $2 p$ photoelectron spectra from i) the same Ti/AlN reaction couple, and from ii) AlN and iii) Al-metal reference samples.

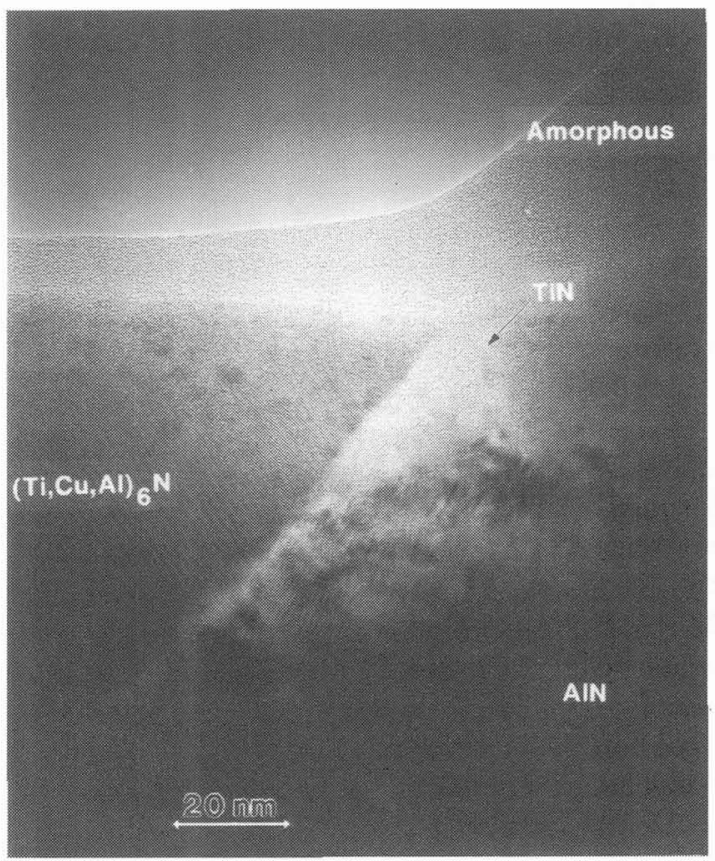

Figure 8. Transmission electron micrograph showing the reaction products that form at AlN/Ti-Ag-Cu interface after $5 \mathrm{~min}$. at $900^{\circ} \mathrm{C}$; both TiN and the $\eta$-nitride phase can be detected.
In reality, the reaction products that form at $\mathrm{Ti} / \mathrm{AlN}$ interfaces are more complex than those suggested by reaction (3). Beyers et al. [29] proposed a $\mathrm{Ti}-\mathrm{Al}-\mathrm{N}$ phase diagram predicting that $\mathrm{TiAl}_{3}$ and $\mathrm{TiN}$ form when Ti reacts with $\mathrm{AlN}$ at $600^{\circ} \mathrm{C}$. Norton et al. [30] reacted $\mathrm{TiH}_{2}$ films with $\mathrm{AlN}$ at $850^{\circ} \mathrm{C}$ and found $\mathrm{Ti}_{2} \mathrm{~N}$ and $\mathrm{Ti}_{3} \mathrm{Al}$ at those interfaces. Because the $\mathrm{Al} 2 p$ binding energies of these different $\mathrm{Ti} / \mathrm{Al}$ intermetallics are virtually indistinguishable from that of $\mathrm{Al}$ and because the $\mathrm{Ti} 2 p$ binding energies of the different $\mathrm{Ti} / \mathrm{N}$ phases are also quite similar, the XPS analyses could not adequately distinguish between those reaction products. However, the development of stable interfacial compounds, whatever their stoichiometries, still supports the suggestion that the addition of reactive components to a conventional braze improves wetting and interfacial bond strength.

The presence of additional alloying elements, particularly $\mathrm{Cu}$, further complicates the interfacial reactions. TEM analysis of $\mathrm{Ag}-\mathrm{Cu}-2 \mathrm{Ti} / \mathrm{AlN}$ interfaces [26] confirmed that $\mathrm{TiN}$ is a reaction product that forms during conventional brazing operations. In addition, a second phase, identified as an $\eta$-nitride with a stoichiometry of ( $\mathrm{Ti}, \mathrm{Cu}, \mathrm{Al})_{6} \mathrm{~N}$, forms between the TiN layer and the remaining $\mathrm{Cu} / \mathrm{Ag}$ alloy (Figure 8). High resolution electron microscopy demonstrated that the AlN/TiN and TiN/n-nitride interfaces are abrupt, with no other crystalline or amorphous intervening phases [26]. These results are consistent with a gradual decrease in the Al- and $\mathrm{N}$-activities, and a gradual increase in the $\mathrm{Ti}$ activity as one moves from AlN across the reaction interface and into the braze alloy; such a gradual change in elemental activity produces the electronic and chemical gradient that is necessary for the formation of a strong metal ceramic bond [31]. 


\section{SUMMARY}

Ceramic-metal joining frequently involves interfacial reactions that promote wetting, spreading, and adhesion. Such reactions have been determined from some ceramic-metal systems of practical interest. The observed phases and their variation with processing conditions can be understood by reference to simple thermodynamic calculations.

\section{Acknowledgment}

The work presented has been done in collaboration with B. Dalgleish, R. E. Loehman, R. K. Brow and A. H. Carim. Grateful acknowledgment is extended to R. M. Cannon, B. Dalgleish and J. A. Pask for extensive discussions and preparation of the figures.

\section{References}

1. A. Adamson, Physical Chemistry of Surfaces, 4th Ed. John Wiley, New York, 1982.

2. B. V. Derjaguim, "Recent Advances in Adhesion", Gordon and Breach, New York (1971).

3. K. H. Johnson and S. V. Pepper, J. Appl. Phys., 53, 6634 (1982).

4. J. E. McDonald and J. G. Eberhart, Trans. Met. Soc., AIME, 512 [233] 512-517 (1965).

5. G. Elssner and G. Petzow, "Metal/Ceramic Joining," ISIJ International, 30 [12], 1011-32 (1990).

6. A. J. Moorhead, Adv. Ceram. Mater., 2 [2], 159-66 (1987).

7. K. Suganuma, Y. Miyamoto and M. Koizumi, Ann. Rev. Mater. Sci. 18, 47-73 (1988).

8. M. Rühle, A. G. Evans, M. F. Ashby and J. P. Hirth, eds., Metal-Ceramic Interfaces, Pergamon Press, Oxford England (1990).

9. M. G. Nicholas, ed., Chapman and Hall, Joining of Ceramics, London, (1990).

10. B. Derby, pp. 319-28 in Ceramic Microstructures '86 Role of interfaces, J. A. Pask and A. G. Evans, eds., Plenum Press, New York, (1987).

11. M. G. Nicholas, "Joining Structural Ceramics," European Colloquium on Designing Interfaces for Technological Applications, CC Joint Research Center, Petten Conference, 1988.

12. R. W. Rice, "Joining of Ceramics," Advances in Joining Technology, J. J. Burke, A. E. Gorum, and A. Tarpinian, eds., Brook Hill Publishing Company, Chestnut Hill, MA (1976).

13. B. Derby and E. R. Wallach, Metal Science, 16 [1], 49-56 (1982).

14. B. Derby and E. R. Wallach, Metal Science, 18 [9], 427-31 (1984).

15. B. Dalgleish and R. M. Cannon, unpublished data.

16. A. G. Evans and B. Dalgleish, Acta Met., 40 Sup. S295-S306 (1992).

17. M. G. Nicholas, Proceedings of MRS Conference on Advanced Ceramics, Tokyo 1988.

18. W. Rostoker, Trans. AIME, 194, 981-2 (1952).

19. R. E. Loehman et al, J. Am. Ceram. Soc., 73 [3] 552-558, (1990).

20. G. Elssner and G. Petzow, "Metal/Ceramic Joining," ISIJ Int'l. 30 [12] 1011-32 (1990)

21. T. Okamoto, ISIJ Int'1. 30 [12] 1033-40 (1990).

22. R. E. Loehman and A. T. Tomsia, Acta Met., 40 Sup. S75-S84 (1992).

23. F. G. Yost and A. D. Romig, Jr., MRS Proc. 108, 385-390 (1988).

24. R. K. Brow et al, Advances in Ceramics, Vol. 26, 189-196 (1989)

25. R. K. Brow et al, Proc. TMS Symp. on Metal Ceramic Joining October 7-11, 1990, Detroit, MI.

26. A. H. Carim and R. E. Loehman, J. Mater. Res., 5 [7] 1520-1529 (1990).

27. C. Ernsberger et al, J. Vac. Sci. Technol., A3 [6] 2415-2418 (1985).

28. C. D. Wagner et al., Handbook of X-ray Photoelectron Spectroscopy, (Eden Praire, MN: PerkinElmer Corp., 1979).

29. R. Beyers et al, J. Vac. Sci. Technol., B2 [4] 781-784 (1984).

30. M. G. Norton et al, J. Mater. Sci., 5 [10] 2172-2176 (1990).

31. J. A. Pask, Am. Ceram. Soc. Bull., 66 [11] 1587-92 (1987). 